\title{
Forum
}

\section{The future of day care in old age psychiatry}

\author{
Christopher J. Ball, Senior Registrar in Old Age Psychiatry, Guy's Hospital, \\ London SE1 9RT
}

\section{Day care in old age psychiatry}

In 1961 Shaw \& Macmillan claimed that there was no doubt of the value of the day hospital as an "alternative to in-patient care and prophylaxis" for the elderly mentally ill (EMI). Thirty years later the day hospital remains central to many EMI services. During these years little has been done to evaluate this method of service delivery against other models of service provision.

\section{Definition and development}

The terms day hospital, day care and day centre are used interchangeably throughout the literature, making comparisons difficult. The following objectives have been given to define day hospitals: rehabilitation, maintenance, assessment and medical, nursing and social care. The day centre is defined "as part of a pattern of services of the social services department providing facilities of care, companionship with social, recreational and occupational activities" (Brocklehurst \& Tucker, 1980). This suggests a considerable overlap between the different entities. The first day hospital was opened in the UK in 1946, since when many day hospitals have been opened with the drive of individual consultants and government support (Vaughan, 1985). Day centres have a shorter history, emerging with the establishment of the local authority social services departments during the 1970 s and the rise of the voluntary sector over a similar period. This dual provision of care has been supported by government policy.

In 1990 the government proclaimed that the local authorities should take the lead in community care. In doing so they failed to establish mechanisms for linking the NHS or trusts to the local authorities in order to develop the 'seamless service'. This creates problems of finance and responsibility for planning which are unfortunate as there is a remarkable concordance of views about community care among the different agencies (Murphy, 1991).

\section{Effectiveness and efficiency}

The evidence that the day hospital is an effective or efficient way of delivering services to an elderly population remains scant. Vaughan (1985) reviewed the literature and despite enthusiasm from some quarters found little evidence to support the idea that day hospitals were more effective than traditional services in younger patients. The extent to which these studies are applicable to an older age group remains a source of conjecture. Cole (1991) looked at geriatric medicine services for insights into the use of day hospitals. He concluded that it is still unclear which kind of continuing surveillance is the most effective in terms of fewer hospital days, or patient well-being. The patients attending the day hospitals did only as well and sometimes worse than those followed up in other ways. This suggests that the old age medicine teams are in a similar predicament with their day hospitals as are EMI teams.

A wide range of activities is undertaken by day hospitals, from the relatively acute management of functional illnesses to the long-term management of patients with dementia. These two distinct populations may experience differential benefits from attendance. Although some stress has been placed upon the day hospital as being of value in the maintenance of depressed patients, none has been clearly demonstrated over other forms of follow-up.

High levels of distress and frank depression are found among the carers of demented patients and this can be relieved by attendance at a day hospital, the degree of benefit being related to the expectations of the carer, with failure to relieve the distress predictive of institutionalisation within six months. No difference in the timing of admissions to an acute ward of groups of attenders and non-attenders of day hospitals has been demonstrated (see Gilleard [1987] for a review).

The benefits described are unlikely to be situation specific and may be greater in day centres. The overlap in functions suggests that the day hospital and the day centre may provide many similar experiences for their clients/patients. 
Greater audit of day hospitals is required. The patients' movement through the system must be considered in depth and the value of specific interventions in establishing robust long-term care packages analysed in greater detail. The setting of long and short-term objectives with regular reviews at multidisciplinary meetings forms the core of this process. This method of working fosters movement through the system and the avoidance of chronic patients accumulating, to the detriment of new referrals, leaving the day hospital merely providing an indirect form of long-term care.

\section{The future}

Travelling 'day hospitals' already function, visiting a number of venues in the district that they serve. The future of day care in the new spirit of the care in the community legislation may owe much to this model. Murphy (1991) envisaged a network of smaller centres more responsive to local needs. These units staffed by vocationally trained people from the social services would be visited by a multidisciplinary EMI team providing assessment and interventions on both a regular and emergency basis. Times of opening could become more flexible to suit carers and if attached to longer stay units respite care and long-term residence may be achieved with the minimum of disruption in an already familiar environment. Care should be provided for life.

\section{Conclusions}

Many of the cornerstones of the health service are currently under scrutiny and day hospitals are likely to come under pressure as they are labour intensive and occupy expensive buildings. Models exist to examine the effectiveness and efficiency of the day hospitals. Claims of relapse prevention, lower admission rates and the values of prolonged assessment and group working over other forms of service delivery such as traditional in-patient/out-patient services or multidisciplinary team-working could be systematically examined. Auditing the existing working practices and assessing the value of specific interventions will enable teams to target better those who will benefit from day hospital attendance. The cost of the various services and interventions needs to be carefully weighed against the quality of the care and their outcome. Day hospitals and day centres provide social contact for the otherwise socially isolated and support over times of crisis. These are services that are best provided in a flexible way as close to the person's community as possible. Community teams working with small local units would be able to target specialist care at those most needy, while giving support and guidance to those providing for the 'ordinary needs' of this group (Murphy, 1991). The age of the day hospital may well be over as new forms of care provision are evolved and evaluated in the new political climate. Opportunities to move in new directions to provide more effective, friendly, flexible and efficient care for the elderly must be seized with enthusiasm and the problems of inter-agency working tackled vigorously.

\section{Acknowledgements}

I am grateful to Professor E. Murphy and Dr J. Herzberg for their comments on early drafts of this paper.

\section{References}

Brocklemurst, J. C. \& TUCKer, J. S. (1980) Progress in Geriatric Day Care. London: King Edward's Hospital Fund.

COLE, M. G. (1991) Effectiveness of geriatric medical services: lessons for geriatric psychiatric services. Canadian Medical Association Journal, 144, 1229-1239.

Gilleard, C. J. (1987) Influence of emotional distress among supporters on the outcome of psychiatric day care. British Journal of Psychiatry, 150, 219-223.

MURPHY, E. (1991) Community mental health services: a vision of the future. British Journal of Psychiatry, 302, 1064-1065.

Shaw, P. \& Macmillan, D. (1961) Nuffield House: a day centre for the psychiatric elderly. Gerontologia Clinica, 3, 133-145.

VAUGHAN, P. J. (1985) Developments in psychiatric day care. British Journal of Psychiatry, 147, $1-4$.

A full reference list is available from the author. 